\title{
POSSIBILITIES FOR APPLICATION OF THE ELECTRONIC SIGNATURE IN THE LAWMAKING PROCESS AT THE ASSEMBLY OF THE REPUBLIC OF NORTH MACEDONIA
}

\author{
Biljana DONCHEVSKA \\ E-mail: b.doncevska@sobranie.mk \\ PhD candidate, Faculty of Law Iustinianus Primus
}

\begin{abstract}
The digital society revolution drives the idea of the level and efficiency by which the public domain and government are ready to use digital tools as well. One of these is "electronic signature", widely used in the private sector as a legitimate tool to identify the person signing a document. Whereas electronic signature is widely practiced as a legitimate means of identifying the signatory of a document, the question arises whether this practice can be introduced in parliaments. Leading hypothesis is the application of electronic signature in the procedure of "sponsoring a bill", or signing the "promulgation act". This hypothesis will be explored from three different aspects: efficiency and transparency benefits, technical infrastructure and safety issues, and current legal frame analysis. Analytical part will also include arguments against the electronic signature, with the risks and threats description, especially the implementation process of such a solution, resistance to introduce changes when parliaments are at stake.
\end{abstract}

Key words: qualified electronic signature, paperless parliament, draft law, promulgation of a law

\section{Introduction}

This article analyses the requirement for the use of electronic signatures in the legislative process, as a legitimate tool to identify a person signing a document. The arguments provided should validate the existence of legal and technical conditions of electronic signatures to be used by authorized signatories in the law making process, members of Parliament, the Speaker and the President of the Republic. Since 2009 the software solution of the eparliament has been implemented in order to digitalize the working process at the Assembly of the Republic of North Macedonia. However, it is necessary to emphasize that this solution does not mean a complete digitalization of the processes in the legislative procedure from the beginning to the end. The electronically obtained documents are printed so as to be hand signed by the authorized signatory, and to be verified with an archive number and a stamp. The verified document is then manually scanned to be entered into the e- 
parliament system. This method is described as inefficient and monotonous. With the introduction of the electronic signature, the electronic seal and the earchive system, these steps would be eliminated and the process of legislative procedure would become fully automated and digitized.

The concept of e-signature, the institutional system to issue electronic signature and issuing procedures are subject to special regulation in a detailed law and sub law regulation. An overview of the legal provisions and regulations relevant in the European Union and Macedonian legislation will be presented. Nevertheless, implementation impediments are inevitable as a result of system inertia to change, especially when parliament is at stake.

\section{Electronic signature}

An electronic signature (e-signature) is an electronic indication of a person's intent to agree to the content of a document or set of data to which the signature refers, providing legal and practical evidence that the person signing a document did, in fact, read or write it and that the document presented is the same as the document signed.

In order to clarify the function of the e-signature, the meaning of the handwritten manuscript signature should be introduced in advance. "The primary function of a physical handwritten signature is to provide evidence of three matters: the identity of the signatory; the signatory's intent that the signature to be his signature; and the signatory's approval and adoption of the contents of the document" (Reed, 2001, p.93). Manuscript signatures meet these functional requirements in a number of ways. Identity of the signature is established by comparing the signature on the document with other signatures that can be proved, by extrinsic evidence. The assumption is that manuscript signatures are unique to persons, and that, therefore, such a comparison is all that is necessary to provide evidence of identity.

Signatures typically serve four functions. First, signatures authenticate signers by providing evidence of their relationship to an agreement. The traditional reliance on signatures is based, in part, on the difficulty of replicating the signatures of other people. Second, a document containing a handwritten signature is valuable because it is presumably original and authentic. Third, signatures represent the affirmative act of signers who, with their signatures, establish the sense of having legally bound themselves to an agreement. Finally, signatures provide a certain level of efficiency, especially when signatures are used to indicate authorization of a transaction (Kalama, Berkeley, 1999, p.469).

Like its handwritten counterpart in the offline world, an electronic signature is a legal concept capturing the signatory's intent to be bound by the terms of the signed document. In short, an e-signature functions to authenticate a document. An e-signature performs this authentication function not by relying on hard-to-imitate handwriting characteristics, but by recording some other 
authentication process or action that would be difficult to imitate, hack or disavow. It must provide evidence of tampering if the document has been manipulated subsequent to being signed and an audit trail to validate the history of the document.

In principle, authentication methods can cover a broad range of techniques extending from relatively simple and vulnerable methods such as email confirmation to more complex and highly secure tools such as private encryption keys and Knowledge-Based Authentication (KBA).

With the growth of the commercial internet in the mid-1990s, technology to support electronic signatures began to gain traction, and the definition of what constitutes an electronic signature has been broadened and formalized. The law also began to catch up with electronic signature technology. When considering the purpose of a model law regarding electronic signatures and the provisions it should contain, it is important to concentrate on why the law is needed. Basically, the need is created because transacting parties want a way to provide trustworthy proof of parties' intent to be bound to their electronic transactions, the same type of trustworthy proof that is currently provided by handwritten signatures on written documents. A model law can authenticate and legally recognize electronic transactions between parties through electronic signatures. Furthermore, the purpose of a model law should be to attain international compatibility between all countries in the world (Braley, 2001). The UNCITRAL ${ }^{1}$ Model Law on Electronic Commerce published by the United Nations in 1996 influenced the global development of electronic signature laws, and led to the creation of the UNCITRAL Model Law on Electronic Signatures. It approved the utilization of electronic signatures, stated that electronic signatures would have the same legal impact as an ink signature and remained technologically-neutral, i.e. did not mandate the utilization of any specific type of technology (Blythe, 2005).

As early as 1999, the Uniform Electronic Transactions Act (UETA) established a framework that allowed for e-signatures and their verification. In 2000, the Electronic Signatures in Global and National Commerce (ESIGN) Act allowed for the use of e-signatures in domestic and international commerce. According to the U.S Electronic Signatures in Global and National Commerce Act, an e-signature is an "electronic sound, symbol, or process attached to, or associated with, a contract or other record and adopted by a person with the intent to sign a record" (2000, S.761 sec.106(5))

Electronic signature and digital signature are often used interchangeably but they represent two different concepts. An electronic signature, like its paper equivalent, is a legal concept. Digital signatures, on the other hand, refers to

${ }^{1}$ UNCITRAL is the body within the United Nations primarily charged with oversight of international commercial law. It was created in 1966 by General Assembly Resolution 2205 (XXI) in order to enable the United Nations to play a more active role in reducing or removing legal obstacles to the flow of international trade (Boss,1998, cited by Smedinghoff and Hill Bro, 1999). 
the encryption/decryption technology on which an electronic signature solution is built. A digital signature alone is not a type of electronic signature. Rather, digital signature encryption secures the data associated with a signed document and helps verify the authenticity of a signed record. Used alone, it cannot capture a person's intent to sign a document or be legally bound to an agreement or contract. The main difference between the two is that a digital signature is mainly used to secure documents and is authorized by certification authorities while an electronic signature is often associated with a contract where the signer has the intention to sign it. A digital signature is the key technology for securing electronic documents against unauthorized modifications and forgery. However, digital signatures require a broader framework, where cryptographic security of a signature scheme is only one of the components contributing to the security of the system. At recent years, private companies are developing rapidly and are open for digitalization, which evolved into the mass application of e-signature in the business world. There are ICT companies that provide e-solutions for public institutions, where safety and quality is guaranteed to international standards.

\section{Electronic signature in EU Law}

Until 2000, only hand-written signatures were legally valid in the EU. The Directive on a Community framework for electronic signature, eSignature Directive 1999/93/EC ${ }^{2}$, adopted in 1999, went into effect in January of 2000 and extended that recognition to electronic signatures.

The eSignature Directive established the legal framework at European level for electronic signatures and certification services. The aim was to ensure the security and legal integrity of communication occurring online by making electronic signatures easier to use and legally recognised within the European Union. Completion of such a legal framework was an essential prerequisite for efficient electronic delivery of public services and for the development of safe electronic transactions. The Directive did not favour any specific technology (Naumovski, Dokmanovik, 2014).

The eSignature Directive was repealed as of 1 July 2016 when the rules on trust services under the eIDAS Regulation, eIDAS EU No 910/2014, came into effect. The eIDAS Regulation defines three levels of electronic signature: 'simple' electronic signature, advanced electronic signature and qualified electronic signature. The requirements of each level build on the requirements of the level below it, such that a qualified electronic signature meets the most requirements and a 'simple' electronic signature the least. An electronic signature is defined as "data in electronic form which is attached to or logically associated with other data in electronic form and which is used by

\footnotetext{
${ }^{2}$ See more: Official Journal of the European Communities L13/12 from 19.01.2000 https://eur-lex.europa.eu/legalcontent/EN/TXT/PDF/?uri=CELEX:31999L0093\&from=EN
} 
the signatory to sign" (eIDAS Article 3). Thus, something as simple as writing your name under an e-mail might constitute an electronic signature.

An advanced electronic signature (eIDAS Article 3) is an electronic signature which is additionally uniquely linked to and capable of identifying the signatory; created in a way that allows the signatory to retain control; and linked to the document in a way that any subsequent change of the data is detectable. The most commonly used technology able to provide these features is the use of a public-key infrastructure (PKI), which involves the use of certificates and cryptographic keys.

A qualified electronic signature (eIDAS Article 3) is an advanced electronic signature which is additionally created by a qualified signature creation device and is based on a qualified certificate for electronic signatures. Signature creation devices come in many forms to protect the electronic signature creation data of the signatory, such as smartcards, SIM cards, USB sticks. "Remote signature creation devices" can also be used where the device is not in the physical possession of the signatory, but managed by a provider. Those remote qualified signature solutions offer an improved user experience while maintaining the legal certainty offered by qualified electronic signatures.

Qualified certificates for electronic signatures are provided by public and private providers which have been granted a qualified status by a national authority as indicated in the national 'trusted lists' of the EU Member State. Those lists can be accessed through the Trusted List Browser. Many providers of qualified certificates will deliver the corresponding private key on a qualified signature creation device. While different levels of electronic signatures may be appropriate in different contexts, only qualified electronic signatures are explicitly recognized to have the equivalent legal effect of hand-written signatures all over the EU.

With the eIDAS Regulation, the EU introduced a single framework for electronic identification and e-signatures. It promotes interoperability across the EU countries, ensuring that a document signed in one EU member can be validated in the other. The eIDAS Regulation establishes a qualification scheme for e-signatures and providers of e-signature services. Qualified esignature service providers can issue certificates to any citizen or business for the creation of qualified e-signatures, legally equivalent to handwritten signatures across Europe.

\section{Application of electronic signature in EU Lawmaking Procedure}

In the European Parliament, amendments and resolutions must be signed by Members of Parliament (Article 169 of the Rules of Procedure (RoP)). MPs cannot delegate their power to sign an amendment or resolution to someone else. At the beginning of 2017, the revised RoP entered into force and the new rule (Rule 168a) stipulated that when a signature is required to meet the threshold, it may be handwritten or in electronic form. Adopting legislation is usually a time-consuming, paper-based process. From the drafting of the legislation to its publication, the document is printed, signed, scanned, 
delivered or disposed many times. Legislative documents tend to be large, the Security of Gas Supply Regulation in all 24 languages, counts over 3000 pages. The signing act requires the physical presence in Strasbourg of signatories representing the European Parliament and the rotating presidency. E-signing with all its benefits improves the legislative process on a number of fronts.

The European Union has entered the age of digitisation, and by signing electronically a legislative act, classified by the lawyers as "body of secondary EU law", the European Parliament and the Council of the EU have sent a political signal to all Member States. To set an example for all of Europe, in 2017 the Council of the European Union and the European Parliament (EP) joined forces to e-sign a European legislation using e-signatures.

On 25 October 2017, Antonio Tajani, President of the European Parliament, and Matti Maasikas, of the Estonian Presidency of the Council, e-signed the new Security of Gas Supply Regulation in support of the digital transformation of the European Union and the Digital Single Market strategy. This demonstrated the EU's commitment to implementing eIDAS, providing for a predictable regulatory environment to enable secure and seamless electronic interactions between businesses, citizens and public authorities. This ceremony marked the first public step at the EU level of the e-signing process. It showed that the EU institutions are working together to make digital transformation a reality and to offer efficient and secure digital solutions in the public sphere.

For the signing ceremony, the European Parliament prepared a signing application, the European Parliament Electronic Signature Console, based on the Digital Signature Service (DSS). DSS is an open-source library for the

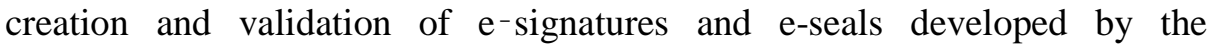
Connecting Europe Facility's (CEF) eSignature building block. DSS was chosen as the engine of the signing application for its out-of-the-box support of the eIDAS Regulation and European standards for e-signatures. In particular, according to the European Parliament, DSS provides full support for the signing of a PDF document, the required format (PDF/A) for the ceremony. DSS also proved highly flexible, being reusable in different topologies, possible to be integrated in its entirety or on a module-by-module basis.

The starting point was the legal analysis, an important step due to the novelty of the use of an e-signing tool in the European legislative process. A first task was to define the level of trust of the used e-signatures. Inspired by the eIDAS Regulation, the chosen e-signature type was the qualified e-signature, legally equal to handwritten signatures. A qualified e-signature guarantees the highest level of security and legal value defined in the Regulation and is acknowledged in all Member States of the EU, necessary for a legislative act of such high-level juridical value.

With the legal aspects clarified, the Directorate-General for Innovation and Technological Support of the European Parliament began to look at the 
technical solution for the job. The initial approach was to use the Parliament's Digital Signature Portal (DiSP). This tool, also based on the DSS library, is used by the Members of the European Parliament to e-sign legislative amendments and the Parliament's civil servants to e-sign administrative forms and documents.

Due to technical and security considerations however, a separate tool was prepared for the signing ceremony, the European Parliament Electronic Signature Console. The Console was built as a stand-alone Java application and offers a number of additional features, some of them specific to qualified e-signatures. For that, the Parliament's ICT Security Unit provided the necessary components, such as trusted certificates, smartcards and access to a timestamp server.

Since the first e-signing of a legislative document has taken place, the Parliament is considering further possibilities for the use of the application, and its potential to be applied in various processes. One of the possibilities is adapting the application and integrating it with the existing internal DiSP portal, allowing a choice of e-signature levels, simple, advanced, or qualified depending on the legal value of the document. Using the application for everyday work will reduce costs and time, increase security and ensure processes can be conducted digitally from beginning to end.

\section{Electronic signature in Macedonian legislation}

Macedonian legislation regulates the usage of the electronic signature through the Law on Electronic Commerce adopted October 2007. In addition, the Macedonian parliament has adopted the Law on data in electronic shape and electronic signature as published in Official Gazette No.34 dated 2001. In 2002, amendments to Article 1 of the law were introduced, removing the part "if not regulated differently by a law". Latest amendments to the Law on data in electronic shape and electronic signature were adopted in 2015, Official Gazette No 33 dated 2015. These amendments introduced change in the subject responsible to deal with electronic signature, namely transferring competences from Ministry of Finance to the Ministry of Information Society and Administration, except for competences for accreditation that were transferred to the Agency on electronic communications.

As of May 2019, this law ceased to exist, being supplanted by a new Law on electronic documents, electronic identification and confidential services. The new law describes in detail the procedures for the use of e-signatures, avoiding the limitations concerning documents that are subject to a notary confirmation. By this law, the application of e-signature is legally possible to all aspects of business. By introduction of new laws mentioned above, concerning the government intention and according to the statement of the Minister of Information Society and Administration, current government strategy is use of paper documents to be minimized as much is possible. 
Subsequently, questions that emerge concerning how e-signature can be used to sign documents in all stages of the law making process, from draft bill to the promulgation act.

Following Art. 137 from Rules of proceedings of the Assembly, the legal procedure commences when the draft bill is submitted and "the Speaker of the Assembly immediately or in three days the latest delivers the draft bill to the Members of the Parliament, in written or in electronic form"(RoP article 137, Official Gazette of Republic of Macedonia, 130/2010).

The expression "electronic form" was introduced in 2009 when the eparliament system was put in place. The Procedure formally is initiated in the Assembly archive sector where the submitted document needs to be archived. Simultaneously this document, electronically received from the bill's sponsor is attached on the e-parliament system. With the electronic system eparliament, the notification time frame is reduced and printing of copy for each Member of Parliament, in total 120 copies is obsolete. However, the original document, in compliance with the archival procedure of the institution, has to be kept in printed version, hand signed and stamped.

In the Rules of proceedings, the expression "signing" is mentioned 18 times, with only one case where it refers to "their hand signed signatures", for a candidate for a Speaker of the Parliament. In the remaining situations there is no specification whether the signing is handwritten although so far in practice is always hand signed. There is an application of an e-signature in the legislature exclusively on signing administrative documents in financial and public procurement matters.

\section{Review of the social conditions required for the electronic signature application}

By nature, the local and central authorities have always been institutions whose functioning is based on paper, due to basic requirements for solid audit tracks, decision-making ability and control. Recently, with increasing pressure on budgets and the need to be more open, many governments have initiated transformational projects to cut out expensive and inefficient paper-based processes. The need to serve citizens and businesses in an automated manner has led governments in many countries to initiate various e-government and eparliament initiatives.

These solutions represent a challenge for every country, regardless of its level of development. The complexity of the entire process, conditioned as it is by many factors, makes the- digitalization process in countries in transition full of challenges. Due to the wider social and sociological impact, the acceptance of the e-services represents long-term processes that demand longer periods to produce positive results.

The process of e-government development as such will fundamentally change the structure, impact and the role of its participants, while at the same time demand from them significant efforts to adjust to the changes. As a result, the implementation of e-services has been met with resistance by some. Although 
resistance is usually more emphasized by the representatives of the public sector, in this case it has been demonstrated more frequently by the users of eservices. The study written by Tosheva and Ugrinovski in 2010 found several reasons why the changes initiated by e-government have been rejected, grouped in two categories: lack of confidence and trust in accordance of the level of protection and confidentiality of data; and resistance to develop new skills, to accept and learn new working techniques and use specific applications.

The implementation of e-services induced radical changes in the functionality of the public sector and its behaviour towards the users. The activities in this field represent combined efforts to introduce the benefits of modern technology while at the same time inducing a transformation of business processes and the manner in which public institutions work.

\section{Discussion and analyses}

As explained in above review, most governments, in particular the US and EU nations, have for some time enacted legislation which recognises digital or electronic signatures as equivalent to hand-written signatures, if produced according to specific requirements. Governments have even gone as far as strongly recommending the use of electronic signatures for specific eapplications. The efficiency in government is largely a matter of executing the small things well. A saved mailing expense or avoided delay can add up to a lot more work for a lot less tax money, which is one practical definition of good government in action. In USA, the savings are estimated at $\$ 5$ for each physical signature that is replaced by an e-signature (Robinson, 2017). In Estonia, for example, every person can provide digital signatures using their ID-card $^{3}$, Mobile-ID or Smart-ID, protected by a personal identification number and containing a digital signature. This enables them to access government services, digitally sign documents, and vote electronically in parliamentary elections. According to these developments, 2\% of Estonia's GDP [gross domestic product] is saved every year (Smith, 2016).

According to the Social Presence Theory, e-signatures evoked a weaker sense of the signer's presence and involvement (Chou, 2015). In addition, in protocolled signing of Declarations, Proclamations and International Agreements with historical value, it is important to achieve a high level of ceremonial act in the signing process. Some of the most significant world's Agreements rely on the ritual of putting pen to paper to please the crowd. For example, when President Obama signed the Patient Protection and Affordable Care Act (colloquially known as Obamacare, in 2010, it marked the most significant regulatory overhaul of the US healthcare system since 1965. Fittingly, he used 22 different pens to sign the document.

\footnotetext{
${ }^{3} 99 \%$ of Estonian residents have ID-card, according to E-Estonia official website, https://e-estonia.com/
} 
Regarding the proof of authenticity of the signatory, as in a case of signing a proclamation by the President of the Assembly and the President of the Republic, and to maintain the ceremonial feature, a possible solution is to use a webcam or video link in the signing process. In order to make signing formal documents by e-signature more convenient, ensuring webcam witnesses is one of the reliable methods.

Use of e-signature could simplify the signing procedure in some urgent situations. For instance, in September 2015, the promulgation act concerning the Law on special prosecutor was sent by plane to Montenegro, where the President of the Republic was on an official visit, to be signed by him in order that the special prosecutor could be nominated in relation to the Przino Agreement. This could have been avoided if the President has had electronic signature to use.

The question on the application of an e-signature in the lawmaking process in the Assembly confirms its relevance by the following arguments:

- Reducing time and financial resources. Law making process is determined by strict deadlines but at the same time distribution of financial resources are subject to enhanced monitoring of how citizens' money is spent.

- Digital society imposes changes and integration in the world of eparliament, e-government, e-petition, e-mandate and in order for this to function and to identify members in this virtual world e-signature is a necessity.

Regarding the advantages of electronic signature, it allows complete digitalization of business processes, elimination of time and cost of printing, sending faxes, sending, copying, scanning and submission in paper form, which eliminates many shortcomings:

- risk of loss, destruction and incompleteness

- difficulty searching, editing and sharing

- need for extensive, physical storage space

By eliminating these loads, the benefits are:

- saving significant time

- improving process security

- reduction of operating costs

- increasing the transparency of the processes

Electronic signing is fast, environmentally friendly, safe and extremely comfortable, contributing to improving the overall experience. The efficiency of interaction, service quality and increased transparency represent the strongest argument for mobilisation of a large number of users from the public sector as well as potential users. For these reasons the currently implemented solutions will have a crucial role in the long-term process of building confidence in e-government. Amongst other things, the task will be to demonstrate the revolutionary character and benefits the users stand to gain from the entire concept.

To ensure similar or even higher levels of authenticity, traceability and control compared to paper processes, e-government and e-parliament solutions have 
an essential need to authenticate digital identities and retain long-term evidence proving who submitted or approved important e-documents.

The e-services solutions can be testified, as long as they are implemented properly, in order to clarify that provided security level could be much higher than the traditional environment.

Arguments that oppose this solution are:

- Change in acceptance and archiving of documents process

- Losing signing ceremony of nationally relevant acts and documents

- Distrust of the system and the loyalty of ICT experts in charge of administration and maintenance.

- Inert public institution to accept changes

Significant efforts to learn new skills and use specific applications usually discourages potential users and forces them to delay their active participation. This point of view leads to the forward opinion of lack of trust to the innovative technologies and their maintenance by the ICT experts. As the 2016 World e-Parliament Report provided by Inter-parliamentary Union (IPU) ${ }^{4}$ observed, "the challenges are not simply matters of adopting technology; many are strategic and need to be addressed at a systemic level" (IPU, 2016, p.77). In order to analyse the opportunities for e-signature application into the legislative process, it might be considered that electronic re-engineering of parliamentary and administrative procedures, which entails transforming daily work processes one by one from (semi) paper-based into a fully-fledged electronic workflow, is supported by a significant change management component. E-signature application is the starting point to the overall digital transformation of the parliaments. The specific set of requirements including legal changes, organizational changes and technical challenges need to be implemented into the Parliaments' Strategic plan. Finally, the significant part of the digital parliament transformation is the training and conducting end users to deal with the digital tools in their everyday working routine. Instead of this, the result might be the framework with duplicated tasks, both electronically and in paper form. To avoid this situation, there is a strong commitment to promote the strategic goal of the paperless parliament. In 2018 World e-Parliament Report it will be concluded that "This is as much a cultural shift as a technological one and it requires a commitment at all levels of the institution to work with others, to see parliament from different perspectives and to be prepared to take risks with new and often untried ideas."(IPU, 2018, p.38)

Increased need for parliamentary e-sessions, that suppose e-signatures, is most relevant in the midst of the Covid-19 pandemic. As recommended, many institutions redirected their working procedures to functioning from a distance using tools and technologies designed for such purpose. Due to this, and

\footnotetext{
${ }^{4}$ Inter-parliamentary Union is the global organization of national parliaments consists of 179 member parliaments including the Assembly of the Republic of North Macedonia, see more on https://www.ipu.org/
} 
following recommendations of international organizations that provide support to the Assembly of the Republic of North Macedonia, the option for e-session has also been raised. The conclusion from ongoing debate may result in amendments to the RoP as well as changes in archive procedures. Application of an e-signature by Members of Parliament, President of the Assembly and President of the Republic to sign a promulgation act, in legal terms is regulated by the above-mentioned Law on electronic documents, electronic identification and confidential services. There is a requirement for amendments to the Rules of Proceedings and Law on Parliament as well as archive functioning within the institution.

In addition to the mentioned changes, the integration and interoperability of the e-systems between the relevant institutions is needed as well. In order for the draft law, which is usually submitted by the government, to be registered in the e-parliament system, it is necessary to integrate the e-parliament and egovernment systems. Also, for the laws that have been declared by decree signed by the President of the Assembly and the President of the Republic, to be passed, it is necessary to integrate the e-parliament system with the electronic system of the Official Gazette. Eventually, the whole process of legislative procedure from the submission of draft laws to the proclamation will be automated and digitized.

\section{Conclusions}

Concerning technical performance, the legal analysis presented before shows that the qualified certificate provides sufficient safety and security in the signatories' authentication process. Namely, the Speaker already holds an electronic certificate to sign administrative documents in the area of e-banking and e-procurement.

Analysis of European and Macedonian legislation dealing with electronic documents and identification of signatories indicates that there is a legal frame to apply qualified electronic signatures opposite to traditional holographic signatures. Electronic signatures can be applied in the lawmaking process since the Rule of Proceedings does not prevent the Speaker or the President of the Republic from signing documents electronically. From the arguments disclosed and the expected results it can be concluded that usage of an e-signature is secure and technically possible.

In order to maintain the ceremonial act of signing historical documents, protocol activities should not be omitted. They can remain the same, with the only difference being that instead of the velvet folders containing the printed document and the expensive ink pens, the signatories will be given a tablet to sign the document electronically with their e-signature appropriated with a security certificate.

Concerning the presented arguments in terms of benefits, challenges and threats, the overall conclusion regarding the specific application of electronic signatures in the legislative process by Members of Parliament and the Speaker is that the system is not completely prepared to implement, not for 
technical reasons but rather the mental attitude and inertia of public institutions to change.

The best way to overcome the subjective obstacles to use the e-services which include usage of e-signature, is to demonstrate the multiple benefits of the process. Legislative process digitalization would help parliaments to carry out their core functions in a bid to make them more open, accessible, accountable and effective. The important consideration is that digital transformation of parliaments as a long term process should be developed as a digital strategy of parliaments established through an incremental project, rather than big-bang implementation. The digital transformation recognizes the necessity of esignature application and it is clarified as the initial approach in tendency for paperless parliament in order to achieve the strategic goal of openness and transparency.

Anyhow, current discourse provides arguments to confirm the practical need to introduce e-signature in the law-making process. Current stay of play provides a realistic basis to pursue the introduction of electronic signature in the legislative process. 


\section{References}

Chou, E. Y. (2015) Paperless and Soulless: E-signatures Diminish the Signer's Presence and Decrease Acceptance, Social Psychological and Personality Science, 6(3), 343-351. Retrieved April 22, 2019 from https://doi.org/10.1177/1948550614558841

Christopher Reed, (2001) Legally Binding Electronic Documents: Digital Signatures and Authentication, The International Lawyer

Electronic Signatures in Global and National Commerce (ESIGN) Act, 2000, S.761

EU Regulation on electronic identification and trust services (eIDAS EU No 910/2014), Retrieved April 18, 2019 from https://eur-lex.europa.eu/legalcontent/EN/TXT/PDF/?uri=CELEX:32014R0910\&from $=\mathrm{EN}$

European Commission Official website, Retrieved April 18, 2019 from https://ec.europa.eu/cefdigital/wiki/display/CEFDIGITAL/Introduction+t o+e-signature,

Goce Naumovski, Misho Dokmanovik, (2014), Law of Information Technology, Faculty of Law Justinian Prima

Gordana Tosheva, ME, Aleksandar Ugrinoski, (2010), Fundamentals and development of e-Government, USAID/e-Government project, Ministry of Information Society, Metamorfozis foundation

Kalama M. Lui-Kwan Berkeley, (1999) Recent developments in digital signature legislation and electronic commerce, Technology Law Journal $\&$ Berkeley Center for Law and Technology

Law on data in electronic shape and electronic signature (Official Gazette of the Republic of North Macedonia 34/2001, /2008, 33/2015)

Law on electronic documents, electronic identification and confidential services (Official Gazette of the Republic of North Macedonia 101/2019, 275/2019)

Nicola K Smith, (2016) Has the hand-written signature had its day? Technology of Business reporter, Retrieved October 22, 2019 from https://www.bbc.com/news/business-37824227

Rick M. Robinson, (2017) e-Signature Security Speeds Government Paperwork Along, Retrieved November 9, 2019 from https://securityintelligence.com/e-signature-security-speeds-governmentpaperwork-along/ 
Rules of Procedure of the Assembly of the Republic of North Macedonia (Official Gazette of the Republic of North Macedonia 130/2010)

Sarah Wood Braley, (2001) Why Electronic Signatures Can Increase Electronic Transactions and the Need for Laws Governing Electronic Signatures, 7 Law \& Bus. Rev. Am. 417, Retrieved November 9, 2019 from https://scholar.smu.edu/lbra/vol7/iss3/7

Stephen E. Blythe, (2005) Digital Signature Law of the United Nations, European Union, United Kingdom and United States: Promotion of Growth in E-Commerce With Enhanced Security, Richmond Journal of Law and Technology

Stephen Manson, (2018) World electronic signature legislation, Retrieved April 26, 2020 from https://www.researchgate.net/publication/329107553_World_electronic_s ignature_legislation

Thomas J. Smedinghoff and Ruth Hill Bro, (1999) Moving with change: electronic signature legislation as a vehicle for advancing e-commerce, The John Marshall Journal of Computer and Information Law, Vol. XVII, No.3, Retrieved November 9, 2019 from www.wildman.com/resources/articlespdf/movingwithchange.pdf

World e-Parliament Report, 2016, Inter-parliamentary Union, Retrieved June 2, 2020 from https://www.ipu.org/resources/publications/reports/201607/world-e-parliament-report-2016

World e-Parliament Report, 2018, Inter-parliamentary Union, Retrieved June 5, 2020 from https:/www.ipu.org/resources/publications/reports/201811/world-e-parliament-report-2018 
